ing the relief; and yet neither I nor the gentlemen who have seen her with me have been able to find, either in the urethra, bladder or reproductive organs, any condition that would suggest a mechanical or reflex cause.

The occurrence of the malignant disease 1 regard as a coincidence merely. It is in this situation, an extremely serious condition, I have seen two, possibly three, similarly situated; and these have been more ulcerative in their character than this. Although 1 cut and burned thoroughly, yet I camnot but feel there is the strongest liability to return of the disease.

I have regarded the development of malignant disease us a coincidence merely, but $I$ an reminded by it of the development of a similar condition about an artificial vesico-vaginal tistula in a patient whom I had the opportunity of seeing with 1)r. Forster. 'This raises the question in my mind as to how far the repoated dilatation might havo been responsible for it.

CAsE IV. The tendency to the formation of villous growths in chronic cystitis is rare, but even less common is it to meet with this condition in the urethra. I have seen it in but a single case, and in this associated with distinct fissure at the neck of the bladder and caruncle at the meatus. The cause of the trouble here was evidently mechanical, the cervix of a retroverted and immovable uterus being crowded hard against the urethra.

Mrs. W., age thirty-nine, consulted me first in June, 1887, for relief from constantly increasing frequency of micturition, accompanied by pain, tenesmus and bloody urine. The pain was of cutting character, and extended up both sides of the pelvis to the back. When it was possible to pass the water in a stauding position the pain was diminished. Under no circumstances could the urine be retained if the inclination to pass it had been felt, and two hours was the maximum interval between the acts for several months past. 'The symptoms dated back about two years, but then the onset had been gradual. 'The urine was quite clear, except for the presence of some free blood. 'The patient had been told that all her troubles were due to the caruncle; but as this had been removed several times without relief, there was evidently some further lesion.

Under ether, by the ondoscope tho urethra was seen to be covered with varicose and dilated blood-vessels in villous outgrowths from the meatus to its junction near the bladder. 'They stopped abruptly here, but there was a deep fissure at the vesical neck upon the lower side. The urethra was thoroughly dilated, its surface scoured and scraped, and painted with a strong solution of urgentic nitrate. 'The walls of the bladder were hypertrophied, and tho cavity would contain about three ounces. 'This treatment was followed by the biweekly injection of a weak solution of nitrute of silver and suppositories; but the latter, as in most of the cases that I have seen, appeared rather to increase the patient's discomfort, and their use was abandoned.

At the same time, I attempted replacement of the uterus, but this was too irritating, and except the employment of a single glycerine tampon placed so as to relieve the urethra us much as possible from preseure of the cervix, was abandoned. 'Tho patient steadily gained, except in the frequency of micturition which I attributed to the same cause largely as in Case 11, it byely, a contracted bladder. Systumatically dilating it by hyperdistention, I had the sutisfaction of over- coming this condition, and in September the patient was so well that she ceased attendance against advice, as 1 felt sure the cervix would again set up tronble.

In January, 1888, the danger-signal of the cutting pain on micturition forced the patient to come arain for treatment. I found two patches, each about the size of a split pea, midway of the urethra, showing the characteristics of a subacute urethritis. With cocaine as an anxstluetic these were quickly dissipated; and at the same time, by packing with great care, I was able to lift the uterus enough to free it from the pressure of the corvix. Since that date the patient has been perfectly well except for the slight locial irritation of the caruncle, which has recurred twice. Should it again appear, I shall make a thorough dissection to remove entirely its base.

It was interesting here to follow the gradual and steady improvement that accompanied the treatment. Few, if any, classes of cases are more exhausting to the nervous strength of the patients than these of vesical disturbance, and the reaction of the local and nervous conditions upon each other are most unhealthy.

'This case is one in which drainage through a vesicovaginal or urethro-vaginal fistula would have been resorted to, I think, by many operators; but, as it was possible to give the pationt all the necessary attention, it seemed to me the more conservative course was the better. Despite all that may be said in their favor, fistula put patients in uncomfortable relations to thensolves and their surroundings ; and one should, I feel, hesitate, and try many conservativo lines of treatment before subjecting a patient to their annoyances and discomforts.

THE INHLUENZA EPIDEMIC AS OBSERVED A'T 'TIIE BOS'ION LYING-IN IIOSI'I'TAL.'

HY OHARLES M. GRKEN, M.U.

'Tin: cases of influenza observed at the Boston Lyingrin Ilospital during the lato epidemic were neither numerous nor severe. liut no unusual complication of tho puerperal state is devoid of interest, and it has therefore seemed worth while to examine the clinical history of these cases with a view to the lessons which they may teach.

The first seizure of the epidemic was observed December 24, 1889; the last, Jinuary 22, 1890. During this period of about a month there were tiftytwo women in the hospital, and among this number there were sevon cases of la grippe, or $13.4 \%,-a$ small proportion probably compared with that obtaining in the community at large.

Case I. Normal primiparous labor, 1)ecember 20 , 1889. Convalescence normal until the morning of the fourth day, when the temperature was $99^{\circ} \mathrm{F}$., and the patient did not feel ivell. Lvening temperature $102^{\circ}$, palse 90 ; complaint of pains all over, with fulness of the head and some coryza, but no sore throut and no cough. Lochia abundant and sweet; no tenderness over the uterus. Warly next morning patient had a chill, and temperature rose to $102.4^{\circ}$, but later dropped to $100.4^{\circ}$; evening temperature $101^{\circ}$, pulse 106. After the chill putient was given quiniz sulph. gr. $x$; but she received no other treatment except occasional mild aperionts or onemata. The temperature fell gradually, was normal on the 
morning of the ninth day, and the patient left the hospital well five days later.

CAsE II. Normal multiparous labor, December 26,1889 . Convalescence normal until the evening of the fifth day, when the patient had a well-marked chill, the temperature rising from $99^{\circ}$ to $102.4^{\circ}$, and the pulse from 70 to 112 : the right breast was somewhat tense and painful and there was some cough. Next morning the temperature was $99^{\circ}$, pulse 72 ; but in the forenoon there was unother chill, with pulse and temperature 84 and $100.4^{\circ}$ respectively. There were no symptoms pointing to any trouble about the uterus, nor was the tense breast, considered sufficient to account for the chills. 'That evening the pulse was 116 , and the temperature rose to $104^{\circ}$ : ten grains of untipyrine were then given, and the next morning the pulse had fallen to $88^{8}$ and the temperature to $99.8^{\circ}$ : the uext day pulse and temperature were normal, and there was no further disturbance. (In the twelfth day, however, when the mother was convalescent, the baby was seized with coryza, conjunctivitis and bronchitis and presented a perfect picture of the catarhal form of the epidemic. 'This was the only case observed among the infants in the hospital.

('AsE III. Normal primiparous labor, l)ecember 27,1889 . 'The lirst stage was tedious, and the patient was rather exhausted, as may be inferred from the pulse and temperature, which did not fall to normal till the morning of the third day from the beginning of labor. (n the morning of the fifth day of the convalescence the temperature was $99^{\circ}$; in the evening it was 101.4, and there was complaint of headache and buckache: lochia normal. In three days these symptoms had disappeared and the temperature was noriual.

('ask JV. A normul primiparous labor, December 22 , 1889, und un uneventful convalescence, except from toothache, until the fourteenth day, when the morning temperature was $102.8^{\circ}$ and pulse 100 . Later in the toorning, there was a chill and the temperature rose to $104^{\circ}$, the patient complaining of pains in the head and back. She was given ten grains of antipyrine, kept in bed, and in two days pulse and temperature were normal.

Cass V. Normal primiparous Jabor and normal convalescence until the sixth day when the patient did not feel well, although the temperature and pulse were normal. 'I'wo days later the breasts were cakey and were rubbed with camphorated oil. Next evening the patient hasd a chill and the temperature rose to $103.4^{\circ}$; there was headuche. Next morning the temperature was normal and there was no further disturbance. 'This may not have been a case of grippe, but it had that appearance; and it did not seem that the subsiding tension of the breasts could have caused the symptoms.

CASE V.I. Wasy primiparous Jabor, January 9, 1890. On the fourth day there was some headache; tenperature normal ; but on the sixth day the temperature rose to $103^{\circ}$ in the afternoon, after quite a severe chill. 'There was some pain in the thighs, but no catarrhal symptoms and no evidence of sepsis. On the following day the morning and evening temperatures were $99.5^{\circ}$ and $102^{\circ}$. A macular eruption with un occasional pustule appeared on the left broast. Next morning the eruption was more extensive, invading the axilla and passing around on the back. Morning and evening temperatures $100.8^{\circ}$ and $100.4^{\circ}$.
Next day the temperature was normal, and two days later the eruption was disappearing.

CASE VII. Rapid, easy primiparous labor, Jannary 10, 1890. Convalescence normal until the ovening of the fiftl day when the temperature rose to $100.6^{\circ}$, with no other symptoms. Next morning a slight macular eruption with an occasional pustule appeared on the right breast, the appearances being similar to those reported in Case VI. In two days the temperature was normul. In this case the elevation of temperature was not marked and the constitutional disturbance not very marked; but the eruption and rise of temperature resembled that observed in Case VI who occupied the next bed but one in the same ward, and the case was thought to be a mild seizure of la grippe.

Of these seven cases it may be said that the symptoms were mild for the most part : in five cases there were one or more chills and decided elevation of pulse and temperature. In two cases there was a macular and pustular eruption: in general the symptoms were headache and backache, malaise with coryza and cough ; but the catarrhal symptoms were mild, except in the case of the laby previously reported. In no case was either nausea, vomiting or diarrlaca observed.

No patient entered the hospital while suffering with influen\%a, so that no opportunity occurred to observe what effect, if any, the disease might have on the progress of labor. Neither was there anv instance of premature labor induced by the epidemic influence. There were several cases, however, who entered while convalescent from the grippe, whose labor and puerperium gave evidence of preceding prostration.

The most serious feature of the epidemic, from the physician's point of view, was the apprehension occasioned by chills and sudden elevations of temperature. In puerperal convalescence such phenomena cannot fail to excite alarm until the diagnosis is clear as to whether the cause is a transient and unimportant one, or whether it is to be attributed to septic absorption. Iu each case, therefore, great care was exercised to accurately explain the changes in temperature before reaching a diagnosis.

Such being the history of the epidemic among the patients, let us briefly examine the experience of the other members of the household. 'The regular complement of attendants embraces six day, and three night, nurses; but during the epidemic there was one vacancy amoug the nurses, and numerous substitutes were employed as occasion required. Of the eight regular nurses four succumbed to the epidemic; and one night nurse was sick enough to have done so, but pluckily attended to her duties. Accurate histories were not kept of the nurses' sicknesses; but thoy were all sicker than any of the patients, with perhaps one exception. One nurse had an evening temperature of $105^{\circ}$, was delirious during the night, and required the attendance of a special nurse: there was backache and great prostration; but the temperature gradually dropped and she was on duty in two days. Another nurse suffered with congh, tonsillitis and prostration for three or four days, with a temperature of $101^{\circ}$ and $102^{\circ}$. Another had an evening temperature of $103^{\circ}$, and was so prostrated by the attuck that, although out of bed in two days, she was obliged to rest for a week before returning to duty.

'Ihe Matron and the Director of Nurses also suc- 
cumbed to the epidemic and were untit for duty for two or three days. Two serving women were also seized, suffering like the others with high temperature, pains in the back and head and great general prostration.

It is interesting to notice the contrast between nurses and patients suffering with the epidemic, in respect to tho severity of thoir symptoms, - the latter suffering much less severely than the former. This was obviously due to the fact that while the nurse was actively at work and frequently overworked, the patient was quiet in bed, in favorable surroundings, and on a more or less restricted diet. It is reasonable to suppose that had the patients been in their own less hygrienic homes, subjected to the mental annoyances and disturbances of family life in average tenement-houses, and without trained nursing they would have suffered much more severely. Indeed, one of the out-patients, who had a long, dilficult lakor, terminated with forceps, was seized with la grippe on the sixth day and was very much sicker than any patient in the hospital. Her evening temperature was $104^{\circ}$, pulse 112 , there was coryza, and severe general pains, even in the fingers. The evening temperature next day was $104.8^{\circ}$, and the following morning it had risen to 105.2 ; but from this point the fever declined and the patient made a gradual, but slow, recovery.

\section{CASES OF CYSTITIS TREATED WITH SALOL,}

BV s. I. A 3 BOL', M.1).

Case 1. On entering on my service at the Massachusetts General Hospital, March 1, 1888, I found in ny female ward a patient who had been admitted on the l2th of February, suffering with severe uterine symptoms and pelvic cellulitis. On the 13th her urine had boen drawn by a catheter for examination and was found to be normal in appearance, acid, of specific gravity 1,020 , containing no albumen, depositing a slight sediment.

The patient's general condition was bad. She was much emaciated, had severe night sweats, and the pelvic symptoms were severe with high temperature up to the 22d, when there was some mitigation of them, but micturition was frequent and painful. $\Lambda \mathrm{t}$ this time the urine was pale, alkuline, of specilic gravity, 1,014, and contained a small trace of albumen, little blood and much sediment of pus and mucus, with triple phosphates.

March lst. Urine strongly ammoniacal, alkaline, otherwise about as on February $22 \mathrm{~d}$.

Palliativo remedies had given considerable rolief, such as washing out the bladder with borax water, and rectal suppositories of morphia, - and acid. nitro-muriatic $\eta_{x v}$ had boen given three times daily. On this day these remedies were omitted with the exception of washing out the bladder. Five grains of chlorate of potash were prescribed to be taken every two hours.

March 2d. After the administration of eight doses of the chlorate, the urine was of normal color and odor, trid, of specitic gravity, 1,018. It contained a slight trace of albumen, and there was some sediment consisting of a small amount of mucus and pus, a little normal blood, and fine and course granular and hyaline cast8. The patient complained of pain in the lower

\footnotetext{
'Roral before the Obstotrioal Soclety of Boston, April I2, 1890.
}

left front chest, and some dry friction sounds were heard at this spot. 'The chlorate of potash was omitted.

March fth. The urine was again alkaline and in other respects as before the use of the chlorate. This, with the bladder washing, was resumed, as the chest symptoms had subsided, and an iron tonic was also prescribed.

There was a gradual increase of strength and on the 12 th the record shows that the patient sat up five or six hours.

On the 16 th, the urine was reported as unchanged, the purulent deposit being one-third of the whole bulk.

March 17th. 'The patient lad been up all the day before and was now complaining of moderate rheumatic pain in the left shoulder and right side. Examination of the chest gave a negative result. All the remedies were omitted, and salol gr. $x$ was directed to be given three times daily.

March 18th. Rheumatic pain relieved, and the urine has undergone a grent change being acid for the first time in two weeks, pale, of specilic gravity, 1,018; containing a small trace of albumen and $a$ greatly reduced sediment. The treatment, was continued until the 24 th when the urine was still acid and contained very little sediment. Salol omitted.

March 25th. Urine alkaline again. As the patient's condition now admitted of a more powerful salicylic romedy, salicylic acid gr. $\mathrm{v}$ was prescribed, to be taken every three hours.

On the 28th the patient was discharged well. She has been seen frequently since leaving the hospital, by my assistant Dr. Greene, and she continues well.

Casi II. Mrs. --_, a young married lady, called on me in the spring of $1888^{\circ}$, complaining of symptoms which shes regarted as uterine, from which she had boen suffering for some days. On inquiry I learned that her most urgent symptom was very frequent micturition (" every five minutes" as she expressed it), a very small quantity of urine being passed at a time, greatly disturbing her sleep at night. 'The trouble was increasing and she asked for a uterine examination to determine the cause. supposing that there must be some displacement of the womb. I learned that sexual intercourse had occurred but twice during the month since marriage, without special suffering.

On making an examination the sphincter vagina was found to be spasmodically contracted and very tender to the tonch, requiring some force to pass the finger beyond it. This having been accomplished, the uterus was found high up in perfectly normal position and condition, neither was there any vaginal tenderness above the os tinca except on the anterior surfuce whero firm pressure towards the bladder caused much pain. There was and had been no vagimal discharge, and the symptoms were clearly rofernble to the bladder. She could suggrest no possible explanation of them. The urine at this time was strongly acid. Palliatives, such as the introduction of a few drops of four per cent. solution of cocaine within the vagina, alkalies, morphine suppositories in the rectum and hot hip baths gave some relief, the urine being alkaline on the following morning.

On the next day the patient complained of loss of appetite, the tongue was furred, and thore had been a chilly turn the day before followed by profuse sweating; she had had intermittent fever in 1884. The urine was acid, specific gravity, 1,01\%, without appre- 